\title{
Degenerated annulus fibrosus of the intervertebral disc contains collagen type II
}

\author{
M. ADAM ${ }^{1}$ AND Z. DEYL ${ }^{2}$ \\ From the ${ }^{1}$ Research Institute for Rheumatic Diseases, Prague, and the ${ }^{2}$ Physiological Institute of the \\ Czechoslovak Academy of Sciences, Prague, Czechoslovakia
}

SUMmaRY Collagen has been isolated and purified from the pronase digest of the outer annulus fibrosus of degenerated and unaffected intervertebral discs obtained at necropsy. The mixture of different collagen types has been purified and fractionated by 2 subsequent DEAE-cellulose chromatographic procedures according to established methods. Collagen chain polymers were then isolated by molecular sieving. Their reduction with 2-mercaptoethanol followed by agarose chromatography resulted in the separation of 3 major peaks corresponding to $\gamma, \beta$, and $\alpha$ chains. Cyanogen bromide $(\mathrm{CNBr})$ peptides and aminoacid analyses revealed the identity of the isolated $\alpha$-chain as $\alpha_{1}$ (III). Further support for this finding was obtained by immunofluorescence. It is suggested that the presence of collagen type III in the outer annulus fibrosus may be related to intervertebral disc prolapse.

The mammalian intervertebral disc consists of 3 different tissues: the cartilaginous endplates of the vertebral bodies, the nucleus pulposus, and the annulus fibrosus, which is classified as fibrocartilage. Chemical studies showed that the annulus fibrosus consists more of noncollagenous material than of tendon and also contains both types I and II collagen. ${ }^{1}$ On the other hand the nucleus pulposus, originating from the notochord, was found to consist of collagen type II only. ${ }^{2}$ However, the boundaries between these subtissues are often indistinct, particularly in the adult. The intervertebral disc changes in character with aging. As the developing fetal vertebral bodies mature to cartilage and afterwards to bone, the portions of the notochord within the bodies are reduced to thin remnants and disappear almost completely within a few years of birth. ${ }^{3}$ Pathologists have reported that after 40 years of age all human spines have degenerative lesions of the discs, particularly in the cervical and lumbar regions. ${ }^{45}$

Further, it has been found that not only in inflamed tissues but also in some so-called degenerative processes-for example, atherosclerosis, osteoarthrosis $^{6}{ }^{7}$ - the proportion of individual collagen types is altered in favour of type III. These findings prompted our search for collagen type III in degenerated annulus fibrosus and intervertebral disc, especially

Accepted for publication 14 February 1983.

Correspondence to Dr M. Adam, Rheumatism Research Institute, Na slupi C 4, 12850 Praha 2, Czechoslovakia. because the collagenous matrix represents the main tensile element of these tissues. It is easy to imagine that such alterations, if they do occur, may be of considerable biological importance.

\section{Material and methods}

Two intervertebral discs (L4 and L5) were obtained at necropsy from the same patient, 72 years old. The disc spaces were narrowed and large osteophytes were present. The degenerative process in both intervertebral discs was verified histologically. An intervertebral disc from a young male aged 25 years and killed in a car accident served as control. After dissection the intervertebral discs were immediately frozen and kept at $-25^{\circ} \mathrm{C}$. The outer annulus fibrosus was carefully dissected to prevent contamination by surrounding tissues, diced, and either pulverized in liquid nitrogen or used for examination by immunofluorescence. Immunofluorescence studies were done on 4 other specimens (patients aged $58,65,68$, 64 years) selected according to the above criteria.

The cartilage homogenate was suspended in $15 \mathrm{vol}$ $4 \mathrm{M}$ guanidine $\mathrm{HC} 1$ buffered with $50 \mathrm{mM}$ sodium acetate (pH 5.8) and rotated for 48 hours at $4^{\circ} \mathrm{C}$. The residue obtained after centrifugation was washed thoroughly with distilled water, and collagen was released by digestion with pronase (collagen/enzyme ratio $100: 1$, at $20^{\circ} \mathrm{C}$ for $40 \mathrm{~h}$ ) as described elsewhere. ${ }^{8}$ The incubation was terminated by centrifug- 
ation, and the supernatant was dialysed exhaustively against water to precipitate the solubilised collagen. This material was centrifuged and used for further determination.

$D E A E$-cellulose chromatography. Proteoglycans were removed from collagen by diethylaminoethyl (DEAE) cellulose chromatography (Whatman DE-52) according to the method of Miller. ${ }^{9}$ In a second DEAE cellulose chromatography types I and III were purified according to the method of Byers $e t$ al. ${ }^{10}$ The column was equilibrated and eluted with

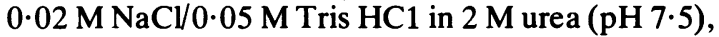
and when no further ultraviolet (UV)-absorbing material was detected the eluting solvent was changed to a linear gradient of $0.02 \mathrm{M} \mathrm{NaCl}$ to $0.3 \mathrm{M}$ $\mathrm{NaCl}$ both in $0.05 \mathrm{M}$ Tris $\mathrm{HC} 1 / 2 \mathrm{M}$ urea ( $\mathrm{pH} \mathrm{7.5)}$. The first peak eluted in this separation contained a mixture of collagen types I and III and was used for further fractionation.

Identification of collagen type III by molecular sieve chromatography. The identification of collagen type III was based on the presence of disulphide bonds in this collagen type and their absence in collagen type $I$. The first major peak from the second DEAE cellulose chromatography was fractionated on a column of agarose beads Bio-gel A $1.5 \mathrm{~m}, 200-400$ mesh, Bio-Rad Laboratories) equilibrated in $1 \mathrm{M}$ $\mathrm{CaCl}_{2} / 0 \cdot 05$ Tris $\mathrm{HC} 1, \mathrm{pH} 7 \cdot 5 .{ }^{11}$ Samples were heated to $40^{\circ} \mathrm{C}$ to ensure denaturation before application to the column.

The fast running fraction from the agarose

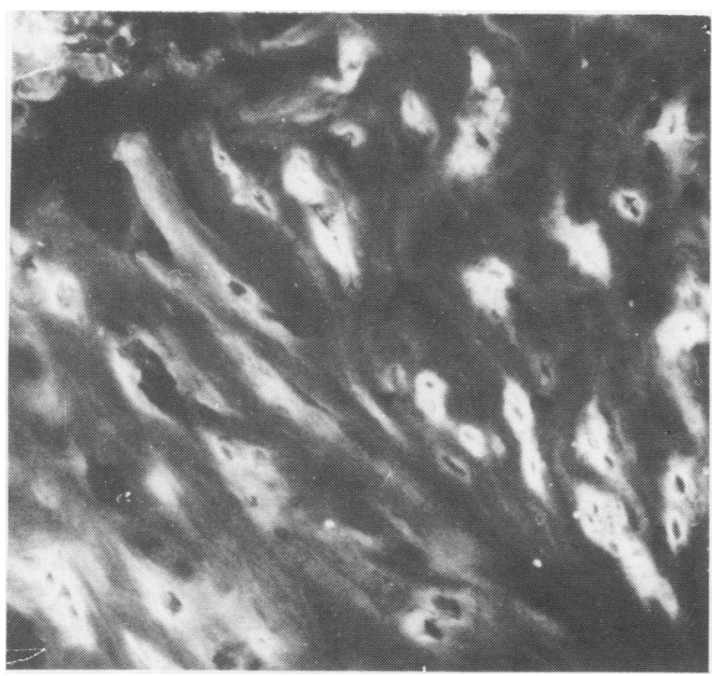

Fig. 1 The annulus fibrosus of degenerated human intervertebral disc. Frozen section stained with anti-type III collagen antibodies. Clusters of cells are surrounded with collagen staining positively for collagen type III. Some collagen fibres are also positively stained. chromatography containing chain polymers of types I and III collagen was reduced and alkylated before being subjected to a second agarose run under operating conditions as above.

Reduction and alkylation. Reduction and carboxymethylation were performed with 2-mercoaptoethanol followed by addition of iodoacetate. ${ }^{12}$ The reaction mixture was desalted on Bio-gel P-2

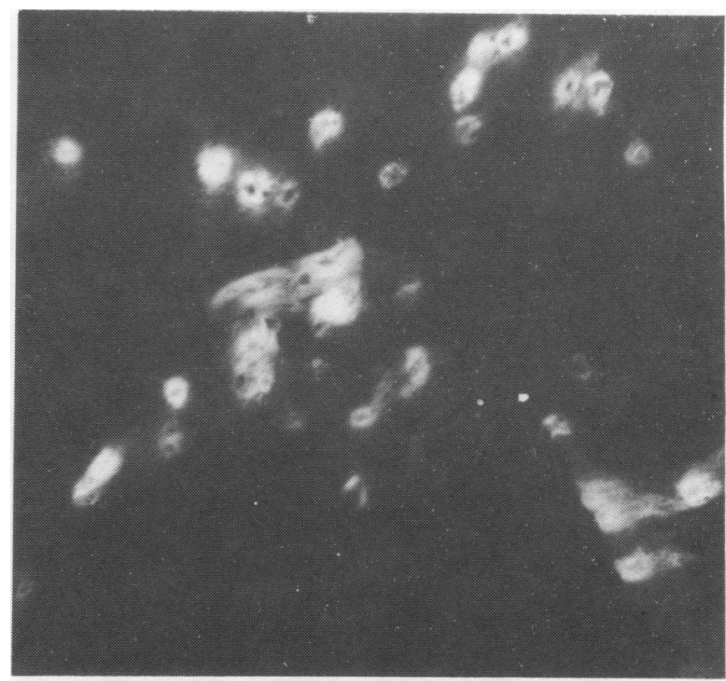

Fig. 2 The annulus fibrosus of degenerated human intervertebral disc. Frozen section stained with anti-type I collagen antibodies. Clusters of cells are surrounded with collagen staining positively for collagen type $I$.

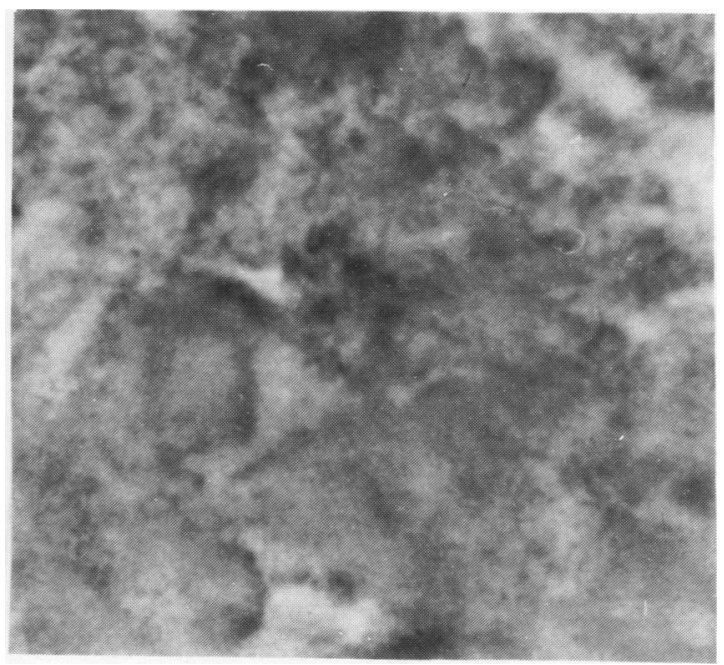

Fig. 3 The annulus fibrosus of unaffected human intervertebral disc. Frozen section stained with anti-type III collagen antibodies. No positive staining. 
(100-200 mesh, Bio-Rad Laboratories) and lyophilised.

Cyanogen bromide cleavage. Collagen was denatured in $70 \%$ formic acid at $50^{\circ} \mathrm{C}$ for $10 \mathrm{~min} .{ }^{13}$ Before heating it $\left(30^{\circ} \mathrm{C}, 4 \mathrm{~h}\right)$ a 15 -fold weight excess of $\mathrm{CNBr}$ was added to the nitrogen flushed solution. The reaction mixture was desalted on Bio-gel P-2 and lyophilised.

Sódium dodecyl sulphate polyacrylamide gel electrophoresis (SDS-PAGE). SDS-PAGE analyses were performed according to the method of Furthmayr and Timpl. ${ }^{14} 12 \cdot 5 \%$ rod gels were used with a current of 5 milliamperes per gel to run the various

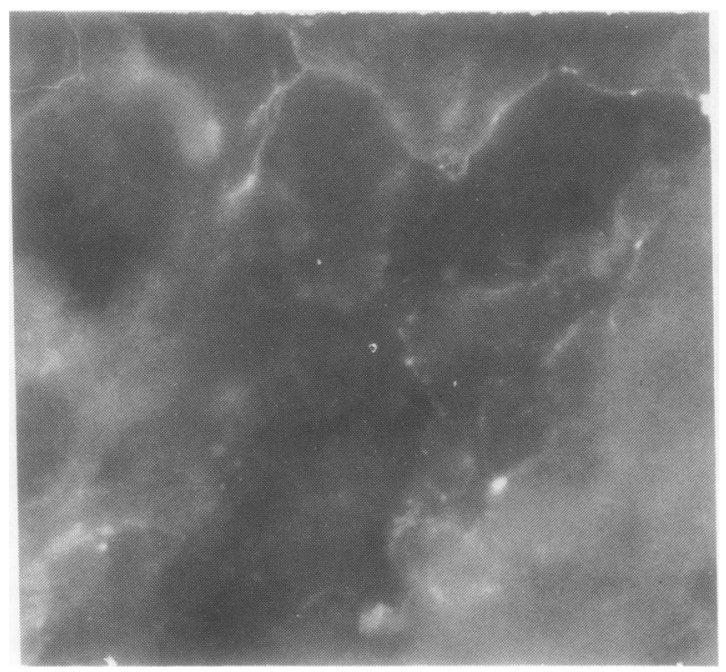

Fig. 4 The annulus fibrosus of unaffected human intervertebral disc. Frozen section stained with anti-type IV collagen antibodies. No positive staining. peptides mixtures. Gels were stained in $1 \%$ amido black in $1 \%$ acetic acid.

Amino acid analysis. Samples for amino acid analysis were hydrolysed in redistilled $6 \mathrm{M} \mathrm{HCl}$ containing $1 \%$ of 2 -mercaptoethanol at $110^{\circ} \mathrm{C}$ in sealed vials under nitrogen. Analysis was done on an automated Durrum D 500 amino acid analyser (Palo Alto, California).

Immunofluorescent staining. Frozen sections were decalcified with $0.3 \mathrm{M}$ EDTA for $30 \mathrm{~min}$, and proteoglycans were largely removed either with hyaluronidase or with $4 \mathrm{M}$ guanidine $\mathrm{HCl}$. After rinsing with phosphate buffered saline, the sections were labelled with rabbit or guinea-pig antibodies to the types I, II, III, and IV collagen $(0.5$ to $0.15 \mathrm{mg}$ per $\mathrm{ml}$ ) for 30 minutes at room temperature, washed in phosphate buffered saline, and counterstained with fluorescein conjugated goat anti-rabbit gammaglobulin or rabbit anti-guinea-pig gamaglobulin diluted 1:10. Purified antibodies against calf types I, III, and IV collagen were prepared from rabbit antisera and rendered specific for the immunising antigen by an appropriate immunoabsorption procedure.$^{15} 16$ Guinea-pig antibodies to chick type II collagen were prepared as described elsewhere. ${ }^{17}$

\section{Results}

The first evidence for the presence of type III collagen (in addition to types I and II collagen) in the annulus fibrosus from the degenerated intervertebral disc was obtained from immunofluorescence labelling experiments (Figs. 1 and 2). Clusters of cells were surrounded by material staining positively for collagens type I and type III. The immunofluorescence staining for collagen type III of an annulus fibrosus obtained from a young patient dual was

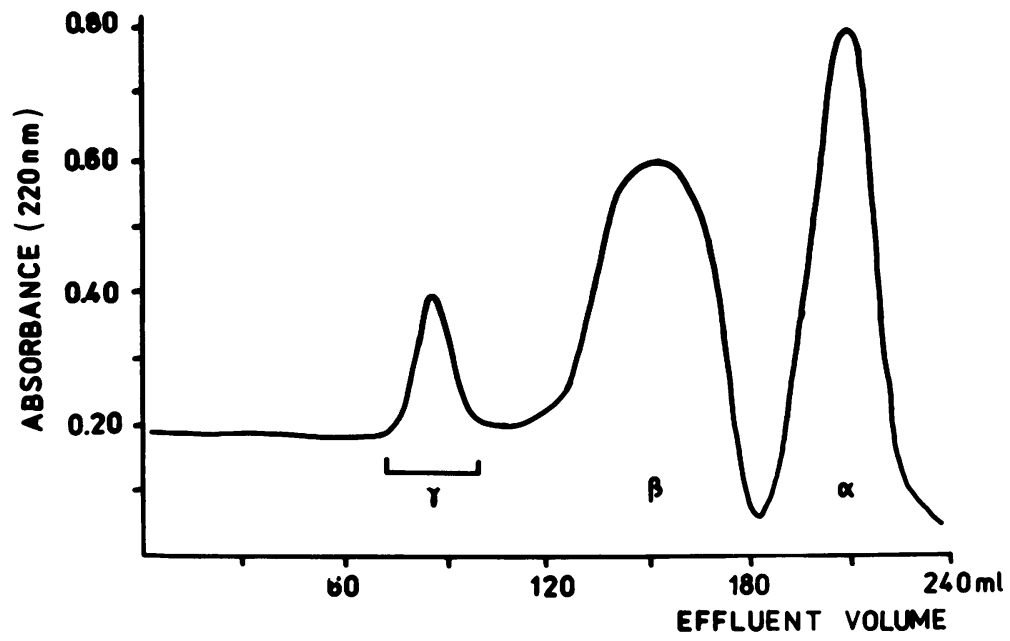

Fig. 5 Molecular sieve chromatography (Bio-gel A $1.5 \mathrm{~m}$, 200-400 mesh) of collagen from the anterior outer annulus fibrosis of a degenerated intervertebral disc previously fractionated twice by $D E A E$ cellulose chromatography. The column $3 \cdot 2 \times 140$ was equilibrated and eluted with $0.05 \mathrm{M}$ Tris- $\mathrm{HCl} / \mathrm{M} \mathrm{CaCl}, \mathrm{pH} 7.5$ at a flow rate $22 \mathrm{ml} / \mathrm{h}$. 
Degenerated annulus fibrosus of the intervertebral disc contains collagen type III 261

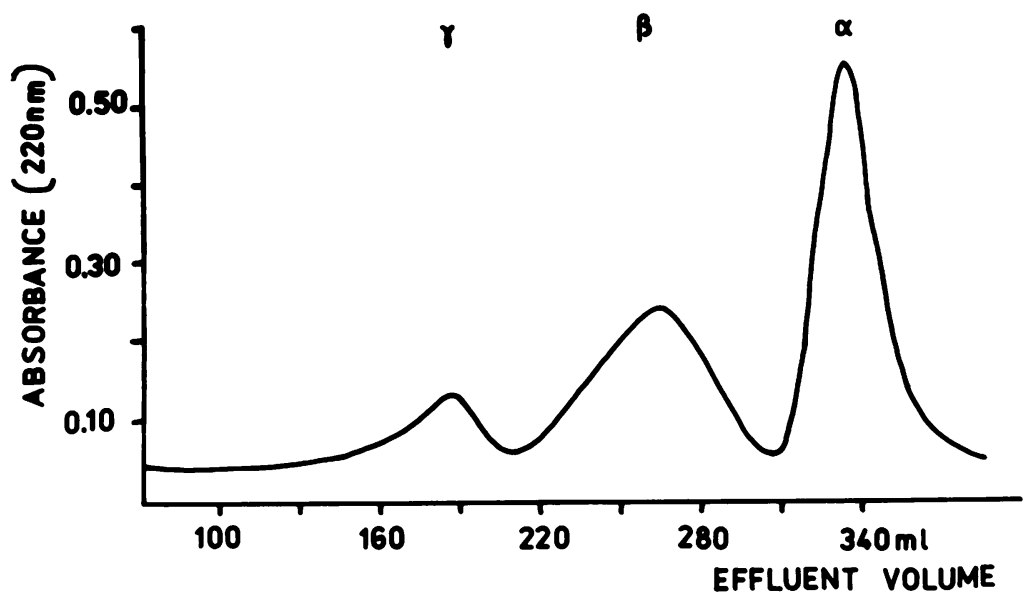

Fig. 6 Molecular sieve rechromatography (Bio-gel $A$ $1.5 \mathrm{~m}, 200-400$ mesh) of reduced and alkylated gamma peak represented in Fig. 5 by solid bar. The column $1.4 \times 146 \mathrm{~cm}$ was equilibrated and eluted with $0.05 \mathrm{M}$ Tris- $\mathrm{HCl} / 1 \mathrm{M} \mathrm{CaCl}_{2}, \mathrm{pH} 7 \cdot 5$ at a flow rate $29 \mathrm{ml} / \mathrm{h}$.

negative (Fig. 3). In the degenerated annuli fibrosi from old individuals, fibres staining positively for collagen type III were consistently found. When frozen sections were stained with antibodies to type IV collagen, the results were negative (Fig. 4).

To confirm the presence of type III collagen by biochemical methods 2 pooled outer annuli fibrosi, L4 and L5 from the same patient, were subjected to pronase digestion. Pooling of samples was necessary to ensure a sufficient amount of material for further assays. The collagenous fraction released was subsequently purified on a DEAE cellulose column and passed over an agarose column A-1.5 M. The elution pattern is shown on Fig. 5. The $\gamma$ fraction indicated by

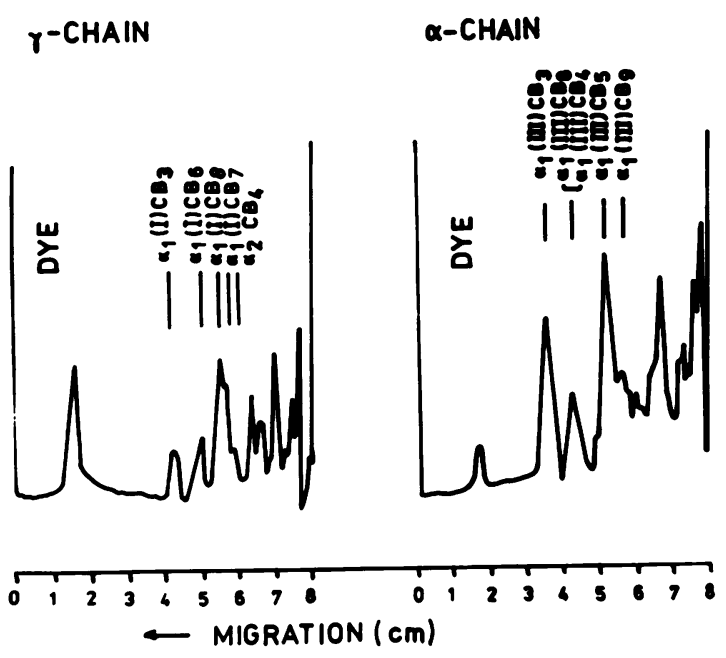

Fig. 7 Densitometric tracing of $\mathrm{CNBr}$ peptides after fractionation by sodium dodecyl sulphate electrophoresis on $12.5 \%$ polyacrylamide gel. Gamma and alpha chains from the second agarose run. the solid bar, which contained chain polymers of type I and III collagen, was reduced, alkylated, and rechromatographed on an agarose $\mathrm{A}-1.5 \mathrm{M}$ column (Fig. 6). Two fractions eluting in the position of $\gamma$ and $\alpha$ components were cleaved with cyanogen bromide, and the peptides were analysed by SDS-PAGE. The densitometric tracing of the amido black stained peptides of the $\alpha$ peak as shown in Fig. 7 resembles a pattern typical for $\alpha_{1}$ (III) chain, whereas $\mathrm{CNBr}$ peptide pattern of the $\gamma$ fraction is typical for collagen type I. The amino acid composition of the $\alpha$ peak is very similar to that calculated from the complete covalent structure of the calf skin type III collagen published by Kühn et al. ${ }^{18-23}$ However, there was a

Table 1 Amino acid composition of alpha chain from molecular sieve rechromatography

\begin{tabular}{lcc}
\hline Amino acid & \multicolumn{2}{c}{ Residues/1000 amino acid residues } \\
\cline { 2 - 3 } & $\begin{array}{l}\text { Annulus fibrosus of degenerated } \\
\text { intervertebral disc }\end{array}$ & $\alpha_{1}(I I)^{*}$ \\
\hline Hyp & 124 & \\
Asp & 45 & 138 \\
Thr & 19 & 48 \\
Ser & 41 & 14 \\
Glu & 67 & 43 \\
Pro & 101 & 67 \\
Gly & 339 & 98 \\
Ala & 97 & 347 \\
Val & 15 & 85 \\
Met & 8 & 13 \\
Ile & 15 & 9 \\
Leu & 16 & 14 \\
Tyr & 4 & 15 \\
Phe & 10 & 2 \\
Hyl & 10 & 9 \\
Lys & 31 & 5 \\
His & 8 & 30 \\
Arg & 49 & 8 \\
Hy & &
\end{tabular}

*According to Kühn et al. ${ }^{18-23}$ 
distinct difference in the content of hydroxylysine: the $\alpha_{1}$ (III) chain of the annulus fibrosus contains 10 hydroxylysine residues compared with about 5 residues in calf skin collagen (Table 1 ). If the $\gamma$ peak from the first agarose run from the young control was reduced and alkylated and rechromatographed over agarose again, $\beta$ and $\alpha$ peaks were absent (data not shown) - that is, collagen type III was not found.

\section{Discussion}

During this study the occurrence of collagen type III was revealed in the degenerated outer anterior annulus fibrosus, while in young unaffected controls this collagen type was not identified. Our data are qualitative because of the complex separation procedure. A rough quantitation, however, showed that the $\beta$ and $\alpha$ peaks from the second agarose chromatography (containing collagen type III) represent $5 \%$ of the total collagen present in the pronase digest. Evidence for the presence of collagen type III is based on the isolation of this protein and its characterisation by amino acid analysis and SDSPAGE profile of cyanogen bromide peptides. These results provide further support for the original evidence based on immunofluorescence techniques.

In connection with the finding of collagen type III in degenerated annulus fibrosus one may ask the question why this particular type of collagen appears in the tissue and what consequences it may have for mechanical function. The type and proportions of collagens present within connective tissue vary with age, development, and pathology. Under different pathological circumstances-for example, acute inflammation, osteoarthrosis, atherosclerosis -either a significant increase of collagen type III occurs or this type of collagen appears de novo. ${ }^{6724}$ However, the absence of immunofluorescence when anti-type IV collagen antibodies were used on the annulus fibrosus of degenerated intervertebral disc led us to conclude that the presence of collagen type III is not related to the invading capillaries. One of the many theories why collagen type III is formed in the degenerated intervertebral disc is that mechanical stress alters the metabolism of the disc's tissue. Overloading can cause degenerative lesions, as was shown in experiments on rats. The pressures involved are sometimes immense: the calculated load on disc L3-L4 is over $300 \mathrm{~kg}$ on lifting. ${ }^{25}$

It should be also emphasised that collagen type III forms fine reticular networks which are more extensible than those formed by collagen type I. This may be related to prolapse of the intervertebral disc. It should be noted that Beard et al., ${ }^{26}$ using an immunofluorescent technique, found collagen type III in scoliotic intervertebral discs. In idiopathic scoliosis other mechanisms causing enhanced concentration of collagen type III in annulus fibrosus may operate.

We are indebted to Professor K. Kühn of the Max Planck Institute for Biochemistry, Martinsried, Federal Republic of Germany, for his kind support and useful discussions. We are also grateful to Ms Marie Krabcová for her expert technical assistance.

\section{References}

1 Eyre D R, Muir H. Collagen polymorphism: two molecular species in pig intervertebral disc. FEBS Lett 1974; 42: 192-6.

2 Eyre D R, Muir H. Type I and type II collagen in intervertebral disk: interchanging radial distribution in annulus fibrosus. Biochem J 1976; 157: 267-72.

3 Eyre D R, Muir H. Quantitative analysis of types I and II collagens in human intervertebral discs at various ages. Biochem Biophys Acta 1976; 492: 29-42.

4 De Palma A F, Rothman R H. The intervertebral disc. Philadelphia: Saunders, 1970.

5 Happey F, Pearson Ch, Naylor A, Turner R L. The aging of human intervertebral disk. Gerontologia 1969; 15: 174-82.

6 Aumailley M, Bricaud H. Collagen synthesis in organ culture of normal and atherosclerotic aortas. Atherosclerosis 1981; 39: 1-9.

7 Adam M, Deyl Z, Miterová L. In: Deyl Z, Adam M, eds Connective tissue research, chemistry, biology and physiology. New York: Liss, 1981: 195-207.

8 Adam M, Fietzek P, Kühn $K$. Investigations on the reaction of metals with collagen in vivo. 2 . The formation of cross-links in the collagen of lathyritic rats after gold treatment in vivo. Eur J Biochem 1968; 3: 411-4.

9 Miller E J. Isolation and characterization of a collagen from chick cartilage containing three identical chains. Biochemistry 1971; 10: 1652-8.

10 Byers P H, McKenney K H, Lichtenstein J A, Martin G R Preparation of type III procollagen and collagen from rat skin. Biochemistry 1974; 13: 5243-8.

11 Piez K A. Molecular weight determination of random coil polypeptides from collagen by molecular sieve chromatography. Anal Biochem 1968; 26: 305-12.

12 Dixit S. Type IV collagens: isolation and characterization of two structurally distinct collagen chains from bovine kidney. Eur $J$ Biochem 1980; 106: 563-70.

13 Bornstein P, Piez K A. The nature of the intermolecular crosslinks in collagen. The separation and characterization of peptides from the cross-links region of rat-skin collagen. Biochemistry 1966; 5: 3460-73.

14 Furthmayr $\mathrm{H}$, Timpl R. Characterization of collagen peptides by sodium dodecylsulfate-polyacrylamide electrophoresis. Anal Biochem 1971; 41: 510-6.

15 Nowack H, Gay S, Wick G, Becker U, Timpl R. Preparation and use in immunohistology of antibodies specific for type I and type III collagen and procollagen.J Immunol Meth 1976; 12: 117-24.

16 Timpl R, Glanville R W, Wick G, Martin G R. Immunochemical studies on basement membrane (type IV) collagens. Immunology 1979; 39: 109-16.

17 von der Mark H, von der Mark K, Gay S. Study of differential collagen synthesis during development of the chick embryo by immunofluorescence I. Preparation of collagen type I and type II specific antibodies and their application to early stages of the chick embryo. Dev Biol 1976; 48: 237-49.

18 Allmann H, Fietzek P P, Glanville R W, Kuhn K. The covalen structure of calf skin type III collagen. VI. The amino acid sequence of the carboxy terminal cyanogen bromide peptide $\alpha_{1}$ (III)CB9B (position 928-1028). Hoppe Seylers Z Physiol Chem 1979; 360: 861-8. 
19 Bentz H, Fietzek P P, Kühn K. Structure of calf skin type III collagen III. The amino acid sequence of the cyanogen bromide peptide $\alpha_{1}$ (III) CB4 (position 403-551). Hoppe Seylers Z Physiol Chem 1979; 360: 833-40.

20 Dewes H, Fietzek P P, Kühn K. Structure of calf skin type III collagen II. The amino acid sequence of the cyanogen bromide peptide $\alpha_{1}$ (III) CB1, 8, 10, 2 (positions 223-402). Hoppe Seylers $Z$ Physiol Chem 1979; 360: 821-32.

21 Dewes H, Fietzek P P, Kühn K. Structure of calf skin type III collagen V: the amino acid sequence of the cyanogen bromide peptide $\alpha_{1}$ (III)CB 9A (positions 789-927). Hoppe Seylers $Z$ Physiol Chem 1979; 360: 851-60.

22 Fietzek P P, Allmann H, Rauterberg J, Henkel W, Wachter E, Kühn K. Structure of calf skin type III collagen I. The amino acid sequence of the amino terminal region of the (III) chain (positions 1-222). Hoppe Seylers Z Physiol Chem 1979; 360: 807-20.

23 Lang H, Glanville R W, Fietzek P P, Kühn K. Structure of calf skin type III collagen IV. The amino acid sequence of the cyanogen bromide peptide $\alpha_{1}$ (III) CB5 (positions 552-788). Hoppe Seylers Z Physiol Chem 1979; 360: 841-50.

24 Adam M, Dostál D, Deyl Z. Collagen heterogeneity in systemic scleroderma and other diseases. J Clin Chem Clin Biochem 1979; 17: 495-8.

25 Eyre D E. Biochemistry of the intervertebral disc. Int Rev Connect Tissue Res 1979; 8: 227-92.

26 Beard H K, Roberts S, O'Brien J P. Immunofluorescent staining for collagen and proteoglycan in normal and scoliotic intervertebral discs. J Bone Joint Surg 1981; 63B: 529-34.

\section{Book review}

Clinical Pharmacology and Therapeutics Series. Vol. 3. Anti-Rheumatic Drugs. Edited by Edward C. Huskisson. Pp. 762.£30•00. Praeger: Eastbourne. 1983.

Fifty-five contributors have prepared the 37 chapters which make up this book. To have prevailed upon all members of the team to toe the line in writing for a book in which topicality is essential represents a considerable feat of editorship, although the task was probably eased by the fact that about half of the authors are directly employed by the pharmaceutical industry and some of the others are known to be closely associated with that influential world in one way or another. Still, as Dr Huskisson remarks in his preface, no apology is really necessary for this: here is where much of the information is readily accessible and where a great amount of research is today carried out. Certainly a workmanlike book has been the outcome.

Initial chapters on classification, the mode of action of arachidonic acid peroxidation inhibitors, and drug interactions are followed by accounts of individual non-steroidal anti-inflammatory drugs (NSAIDs), analgesics, corticosteroids, gold, penicillamine, other thiol compounds, levamisole, azathioprine, chlorambucil, antimalarials, and synoviorthesis. Among the NSAIDs zomepirac is included but methrazone is omitted. The closing chapters consist of viewpoints, necessarily with a personal bias, on the integrated drug treatment of rheumatoid arthritis, SLE, gout, and Paget's disease, with a final section on assessment for clinical trials.

The editor has clearly allowed his colleagues considerable freedom. This has resulted in disproportionate length (or brevity) of the various chapters. For example, corticosteroids receive 10 pages, indomethacin 14 pages and diclofenac sodium (hardly the last word in treatment) no fewer than 50. Most of the contents are of course modern in the extreme, although there are one or two nice flashbacks, such as the recommendation that gastrointestinal distress caused by colchicine ( $1.0 \mathrm{mg}$ every 2 hours) should be treated with 'a gastric sedative, such as tincture of camphorated opium'. The staff of the excellent pharmacy at Charing Cross Hospital inform me that this time-honoured remedy is no longer held in stock and could be prepared only by very special arrangement; it does, however, remain in the B.P. No doubt we are the poorer from this loss of pharmacoavailability.

The book is recommended as an admirable reference work.

J. T. SCOTT 


\section{Notes}

\section{Rheumatology Research}

The 5th EULAR Workshop on Rheumatology Research will take place at the Jolly Hotel Milano 2, Segrate, Milan, Italy, on 1-2 March 1985. The official language will be English, and there will be no simultaneous translation. Preselected posters will be discussed in the 5 plenary sessions ( 4 min +2 slides per poster). All abstracts should be submitted before 31 December 1984 and will be published in Clinical and Experimental Rheumatology. Further information from Professor Raffaele Numo, Cattedra di Reumatologia, Policlinico, Piazza Giulio Cesare, 70124 Bari, Italy.

\section{Panhellenic Congress}

The 9th Panhellenic Congress in Rheumatology will be held in Athens at the Athenaeum Intercontinental Hotel on 22-24 November 1984. The topic is 'Advances in connective tissue diseases.' Details from Dr John Lalos, 4 Papadiamandopoulou Street, Athens 612, Greece.

\section{Implant surgery}

The 15th Annual International Symposium on Implant Surgery for the Hand and Upper Extremity will be held on 25-27 October 1984 at the Blodgett Memorial Medical Center and Amway Grand Plaza Hotel, Grand Rapids, Michigan, USA. Details from Dr Alfred B. Swanson, Blodgett Professional Building, Suite 290, 1900 Wealthy Street, SE, Grand Rapids, Michigan 49506, USA.

\section{Marisa Ara prize}

This prize of 2 million Italian lire will be awarded to a woman for research in rheumatology published within the last five years. Entries must be received by 31 July 1984. Information from Professor Carla Caianicllo, Via Posillipo 102-2, 80123 Napoli, Italy.

\section{Corrections}

The title of the paper by M. Adam and Z. Deyl (Ann Rheum Dis 1984; 43: 258-63) should have read: 'Degenerated annulus fibrosus of the intervertebral disc contains collagen type III' (not type II). We regret the error.

In the paper by T. Pullar, J. A. Hunter, and H. A. Capell entitled 'Does second-line therapy affect the radiological progression of rheumatoid arthritis?' Ann Rheum Dis 1984; 43: 18-23 we regret that an error occurred on p. 22. The fourth (new) paragraph should read: 'Conversely, with the number in our study we would have required a difference of over 10 between the change in the "control" and treatment radiograph scores to demonstrate a significantly beneficial drug effect. We were, however, only able to demonstrate a difference of 3.87 between gold and "control" groups and only 3.3 between "control" and penicillamine groups". 